\title{
OBSERVATIONS ON THE INFRARED ABSORPTION SPECTRUM OF BACTERIOCHLOROPHYLL
}

\author{
by \\ J. G. KOMEN * \\ Biophysical Research Group Utrecht-Delft, under the direction of $A$. J. Kluyver, Delft, \\ and $J, M . W$. Milatz, Physical Institute, Utrecht (The Netherlands)
}

\section{INTRODUCTION}

The infrared absorption spectra of various purple bacteria do not always coincide. For example, that of the Thiorhodacea Chromatium strain $\mathrm{D}$ shows three absorption bands at about 8900,8500 , and $8000 \mathrm{~A}$, while in the infrared spectrum of the Athiorhodacea Rhodospirillum rubrum only one major absorption peak at about $8800 \mathrm{~A}$ and a very weak one at about $8000 \mathrm{~A}$ is observed.

In aqueous extracts of photosynthesizing bacteria the absorption spectrum is similar to that of intact bacteria. However, in extracts with organic solvents the spectra are markedly different; only a single maximum occurs at about $775^{\circ} \mathrm{A}$, irrespective of the species from which the extract is prepared. Thus it seems that the in vivo spectra of purple bacteria, though they may be mutually different, are due to the presence of the same kind of bacteriochlorophyll, $c f$. KATZ AND WASSINK ${ }^{1}$, and RABINOWITCH ${ }^{2}$.

In order to obtain more insight into the conditions determining the infrared absorption spectra of bacteriochlorophyll, solutions of purified bacteriochlorophyll as well as aqueous extracts of purple bacteria were examined. The main results of this study are presented here.

\section{METHODS}

Isolation of bacteriochlorophyll. The contents of a $50 \mathrm{ml}$ glass-stoppered flask containing a culture some months old of Rhodospirillum rubrum strain 4 was centrifuged. The sediment was washed with $0.2 \mathrm{M} \mathrm{Na}_{2} \mathrm{HPO}_{4}$ and centrifuged again. The centrifugate was ground in an agate mortar with $\mathrm{SiO}_{2}$, "silversand", and $\mathrm{MgCO}_{3}$ after addition of about $3 \mathrm{ml}$ acetone. Then, the intensely colored acetone was decanted over cotton wool. The latter was washed with fresh acetone until the passing

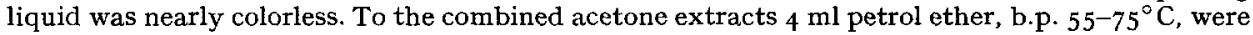
added. Next the acetone was removed from this mixture in a water-filled separatory funnel by introducing the extract with the aid of a vertical micropipette, the end of which was bent I 80 degrees, below the water surface. By allowing the extract to flow gently out of the pipette this liquid rose to the surface in droplet form. This procedure was repeated tenfold after changing the water each time. At the end of these washings a blue sediment was formed partly on the wall of the

* Illness and the subsequent so lamentable death of the author on I 7 th June, I955 prevented him from preparing this paper. The experimental data and notes left behind by him have been edited by Mr. Y. D. LoopstRA, who participated in part of the investigation, together with Dr. J. B. Thomas.

References $p . T 5$. 
funnel and partly at the petrol ether-water interface. The later sediment was isolated by centrifugation and dissolved in a small quantity of ether. With this solution the wall of the funnel was rinsed. The resulting solution was evaporated in a current of nitrogen. The residue was taken up in a small amount of $\mathrm{CCl}_{4}$. The same quantity of petrol ether was added and the mixture was chromatographed over a saccharose column. The column was developed with a mixture of $\mathrm{CCl}_{4}$ -petrol ether-acetone, 45:45: $\boldsymbol{1}$ o. A relatively sharp blue band, preceded by two pink ones, was isolated. This solution was stored at $-10^{\circ} \mathrm{C}$ in the dark. For use, a few drops of the solution were "dried" by evaporation in a current of nitrogen and dissolved in the solvent to be tested. After a six day storage the spectrum did not change. In a five weeks old sample the spectrum was somewhat flattened.

Preparation of aqueous extracts. Cultures of either Chromatium strain D or Rhodospirillum rubrum strain 4 in liquid media were centrifuged for 25 minutes at $1200 \mathrm{~g}$. The supernatant was decanted and the bacterial sediment was thoroughly washed with a $0.2 M \mathrm{Na}_{2} \mathrm{HPO}_{4}$ solution. The suspension was centrifuged again. The sediment was ground in an agate mortar with carborundum, grain diameter $0.05 \mathrm{~mm}$, for 20 minutes. Next, about $5 \mathrm{ml}$ distilled water were added and, after stirring, the carborundum was allowed to settle down. The supernatant was preserved. This procedure was repeated twice. The combined supernatants were twice centrifuged at $2000 \mathrm{~g}$ for 20 minutes. Centrifugation was repeated once more at $12000 \mathrm{~g}$ for 45 minutes. All sediments were discarded. The final supernatant, which was still intensely colored, was used in the experiments as "crude" extract. "Purified" extract was prepared by centrifuging the "crude" one at I $2000 \mathrm{~g}$ for two hours. The slightly colored supernatant was discarded and the sediment was taken up in a few $\mathrm{ml}$ distilled water. If necessary, this procedure was repeated. The infrared absorption maxima of "purified" extracts from Rhodospirillum rubrum were shifted to the short wavelength region about $50 \mathrm{~A}$ as compared with those of the "crude" extracts.

\section{RESULTS}

\section{Experiments with purified bacteriochlorophyll}

Since it is possible to influence the spectral properties of chlorophyllous pigments ${ }^{2-6}$, experiments were carried out to study the effect of some solvent mixtures on the bacteriochlorophyll absorption spectrum.

(a) Ether-petrol ether mixtures. Addition of moderate amounts of petrol ether to a solution of bacteriochlorophyll in ether did not cause any shift of the absorbtion maxima. However, at increasing concentrations of the former solvent a decrease of the peak heights was observed. Fig. I shows theabsorption spectrum in a $I: I \mathrm{mix}-$ ture.

(b) Benzene-water mixtures. The spectra in dry benzene were found to be identical with those in benzene saturated with distilled water. The maxima were shifted to

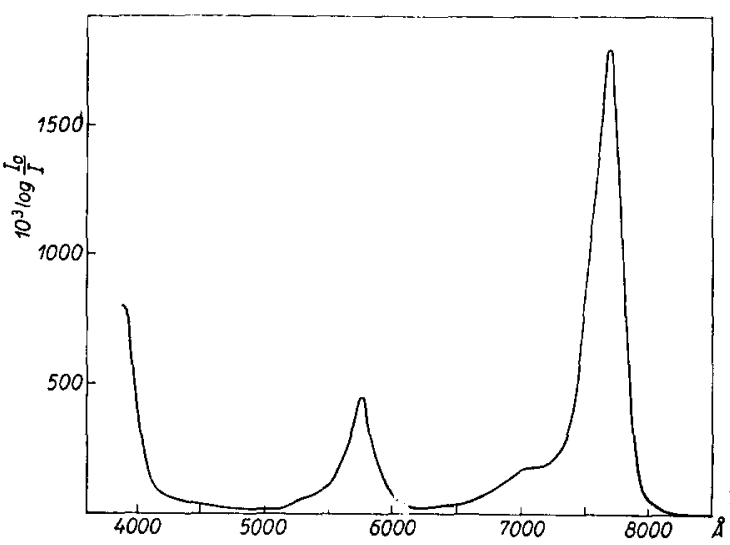

Fig. I. Absorption spectrum of bacteriochlorophyll in a $\mathbf{I}: \mathbf{r}$ mixture of ether and petrol ether.

the long wavelength side over a distance of $75 \mathrm{~A}$ when compared with those in the mixtures mentioned in (a). Aerobic emulsification of such a solution in distilled water yielded a pink color. By this operation pheophytinisation occurred. This phenomenon could be prevented by using a o.I $N \mathrm{KOH}$ solution instead of water.

(c) Acetone-water mixtures. Addition of distilled water to a bacteriochlorophyll solution in acetone up to $45 \%$ did not influence the spectrum. Theinfrared absorption peak was located at $775^{\circ} \mathrm{A}$. At water percentages between 45 and 55 an additional 
maximum at $8500 \mathrm{~A}$ was formed while, concomitantly, the $775^{\circ} \mathrm{A}$ peak was reduced. This is shown in Fig. 2. Fig. 3 demonstrates that on increasing the water percentage

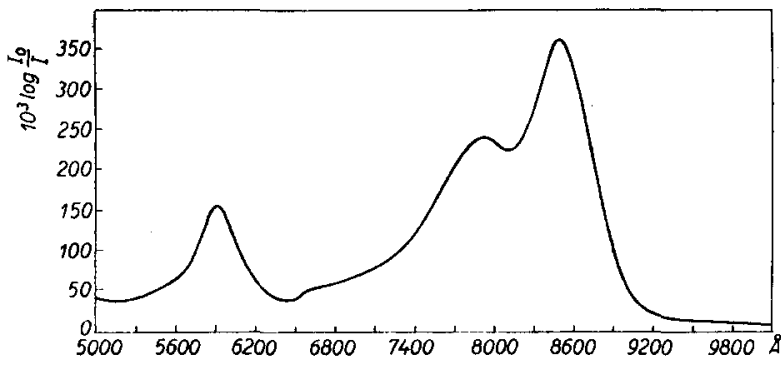

Fig. 2. Absorption spectrum of bacteriochlorophyll in a 45:55 mixture of acetone and water.

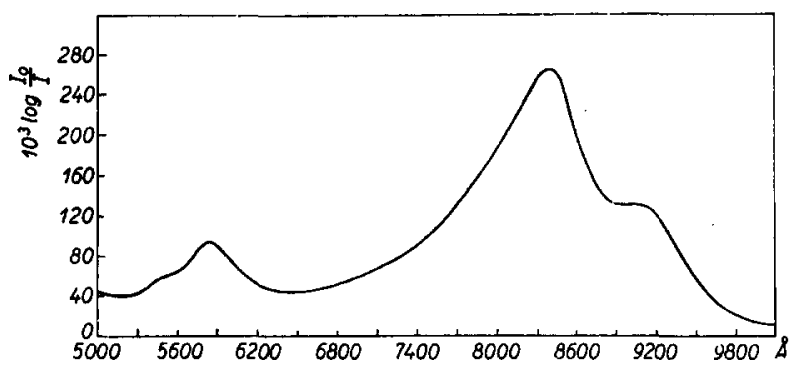

Fig. 3. Absorption spectrum of bacteriochlorophyll in a Io:90 mixture of acetone and water.

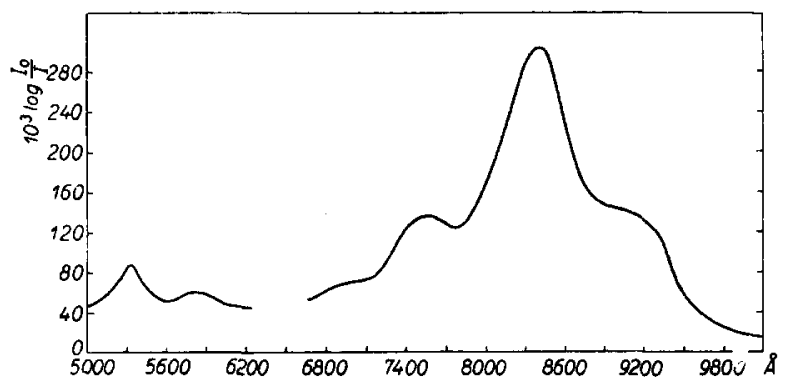

Fig. 4. Absorption spectrum of bacteriochlorophyll in a I0:90 mixture of acetone and water in the presence of SDS at pH 5 . up to 90 the $7750 \mathrm{~A}$ peak was still more reduced while a second additional maximum arose at about $9200 \mathrm{~A}$. The latter maximum vanished at water percentages surpassing 98 . Both additional peaks could be made to disappear again by adding acetone up to a percentage of at least $\mathbf{5 5}$.

(d) Acetone-water-salt mixtures. Contrary to data mentioned in literature ${ }^{4,5}$, addition of a few drops of a saturated $\mathrm{CaCl}_{2}$ solution in water to a I:I mixture of acetone and water prevented the formation of absorption peaks at wavelengths exceeding $7750 \mathrm{~A}$. Combined addition of calcium chloride and ammonia had the same effect. Addition of a few urea crystals to a $I$ : I acetonewater mixture did not bring about any change.

(e) Acetone-veater I:9-SDS mixtures. The influence of the detergent sodium dodecyls ulfate, SDS, at a concentration of $0.2 \%$ was studied at $\mathrm{pH}_{5}-\mathrm{O}$. $M \mathrm{NaH}_{2} \mathrm{PO}_{4}$ - and $\mathrm{pH} 8-$ o.I $M \mathrm{Na}_{2} \mathrm{HPO}_{4}$-. At pH 8 the spectrum resembled that of Fig. 2. No 9200 A peak was observed. After three days in the dark and at $-10^{\circ} \mathrm{C}$ the $8500 \mathrm{~A}$ maximum was reduced to $25 \%$ of its original height while the height of the $7750 \mathrm{~A}$ maximum was slightly increased. The spectrum at $\mathrm{pH}_{5}$ is shown in Fig. 4. The 9200 A peak was present while the $7750 \mathrm{~A}$ peak was nearly absent. The formation of absorption maxima at 5300 and 7600 A showed the occurrence of pheophytinisation. After three days the height of the $8500 \mathrm{~A}$ peak was slightly increased while that of the remaining part of the studied spectral region was slightly decreased.

(f) Acetone-water I:9-agar $0.2 \%$ mixtures. Addition of $0.2 \%$ agar prevented the formation of the $9200 \mathrm{~A}$ maximum. This was true also in a buffered mixture at $\mathrm{pH} 5$. In the latter case a slow pheophytinisation occurred. 
All mixtures showing an 8500 A absorption maximum were slightly opalescent.

\section{Experiments with bacteriochlorophyll in the natural state}

Particle size. It was stated by PARDEe, Schachman AND STANIER ${ }^{7}$ that in aqueous extracts from Rhodospirillum rubrum only particles with a weight of $3 \cdot \mathrm{Io}^{7}$ times the weight of a hydrogen atom occurred. This result could be confirmed in the present experiments. The particle weight was determined by both sedimentation rate at I0000 $\mathrm{g}$ and electron microscopical observation. Both techniques yielded a value of about $3 \cdot \mathrm{IO}^{\text {? }}$.

Stability. The extracts were resistant to storage in light and air; no spectral change was observed. After a few days storage in the dark at $4^{\circ} \mathrm{C}$ a precipitate was often formed. This effect could not be prevented by filtration, sterilisation by filtration, or addition of enzyme inhibitors. According to MAcheBoeUF ${ }^{8}$ the same phenomenon occurs upon storing lipoprotein fractions from blood serum.

Denaturation of the bearer compound. Addition of urea in high concentration $(50 \%)$ did not affect the absorption spectrum. Since urea is known to be a strongly denaturating agent for proteins, it seems that considerable structural changes of the pigment bearer may occur without alterations of the interaction of this compound and bacteriochlorophyll.

It is stated in literature, $c f$. PolonovsKY ${ }^{9}$, that detergents act strongly on proteins and, in particular, on lipoproteins. Two kinds of detergent-protein complexes are described. In one of them the ratio of the amounts detergent/protein is $1 / 3$ while for the other type this ratio is reversed. In experiments with a final concentration of $25 \%$ SDS no appreciable changes in the absorption spectrum could be observed. At an SDS concentration of $75 \%$, however, the spectrum was affected. In extracts from both Chromatium and Rhodospirillum rubrum the absorption band at about $8800 \mathrm{~A}$ disappeared at $\mathrm{pH} 8.0$ and 5.5. Moreover, for Chromatium at $\mathrm{pH} 8.0$, the absorption bands at 8500 and $8000 \mathrm{~A}$ were unaffected while a new peak at $7800 \mathrm{~A}$ arose. At pH 5.5, however, the 8500 and $8000 \mathrm{~A}$ bands were reduced after a while and a new band at $7600 \mathrm{~A}$, indicating the formation of bacteriopheophytin, arose. Apart from the disappearance of the $8800 \mathrm{~A}$ band, an increase of absorption at $7800 \mathrm{~A}$ was observed in Rhodospirillum rubrum extracts at $\mathrm{pH} 8.0$. At $\mathrm{pH} 5.5$ the $7600 \mathrm{~A}$ band was also formed in these extracts. As it was found ${ }^{10}$ that no spectral changes in the pigmentbearer complex occur above $\mathrm{pH}_{4.5}$, it is likely that the above changes are due to the action of SDS.

Recombination experiments. In order to decide between the possibilities that the three-peaked infrared absorption spectrum of Chromatium is due to the presence of either three different bacteriochlorophylls or to three different bearer compounds, the following experiments were carried out. An aqueous Chromatium extract was decolorised by removing the pigments with acetone. The flocculated protein fraction was washed and taken up in distilled water. By this procedure, however, the major part, if not all, of the proteins was rendered insoluble. To this suspension pure bacteriochlorophyll was added under vigorous stirring. The bacteriochlorophyll was isolated from Rhodospirillum rubrum, which, in vivo, shows only one major infrared absorption maximum, and dissolved in a small amount of acetone. The reverse was also done; bacteriochlorophyll from Chromatium was added to depigmented proteins from Rhodospirillum rubrum. It was hoped that it would be possible to find out 
whether the three-peaked spectrum occurred either in the presence of the proteins or in that of the bacteriochlorophyll from the organism with such a spectrum. The results were discouraging; in both cases two maxima were formed. One of them was located at $8400 \mathrm{~A}$, the other one at 9roo A. Probably, some denaturation of the depigmented proteins was at least one of the factors that made the experiment inconclusive.

Though such a "crossing" between pigments and bearers could not be realized, it proved possible to recombine bacteriochlorophyll with its natural bearer after isolation. This was done by adding acetone up to $80 \%$ to an aqueous extract from Rhodospirillum. Within ten minutes the 8800 A maximum had disappeared and a $7800 \mathrm{~A}$ maximum, characteristic for isolated bacteriochlorophyll, was formed. Either immediately, or after periods of I to 5 hours, distilled water was added till the ultimate acetone concentration was $20 \%$. The results are shown in Fig. 5. At $a$ the spectrum of the used aqueous extract is represented. $b$ shows the spectrum after addition of 4 volume units of acetone. It coincides with the usual spectrum of bacteriochlorophyll in acetone. From $c$ it is evident that, after reducing the acetone concentration to
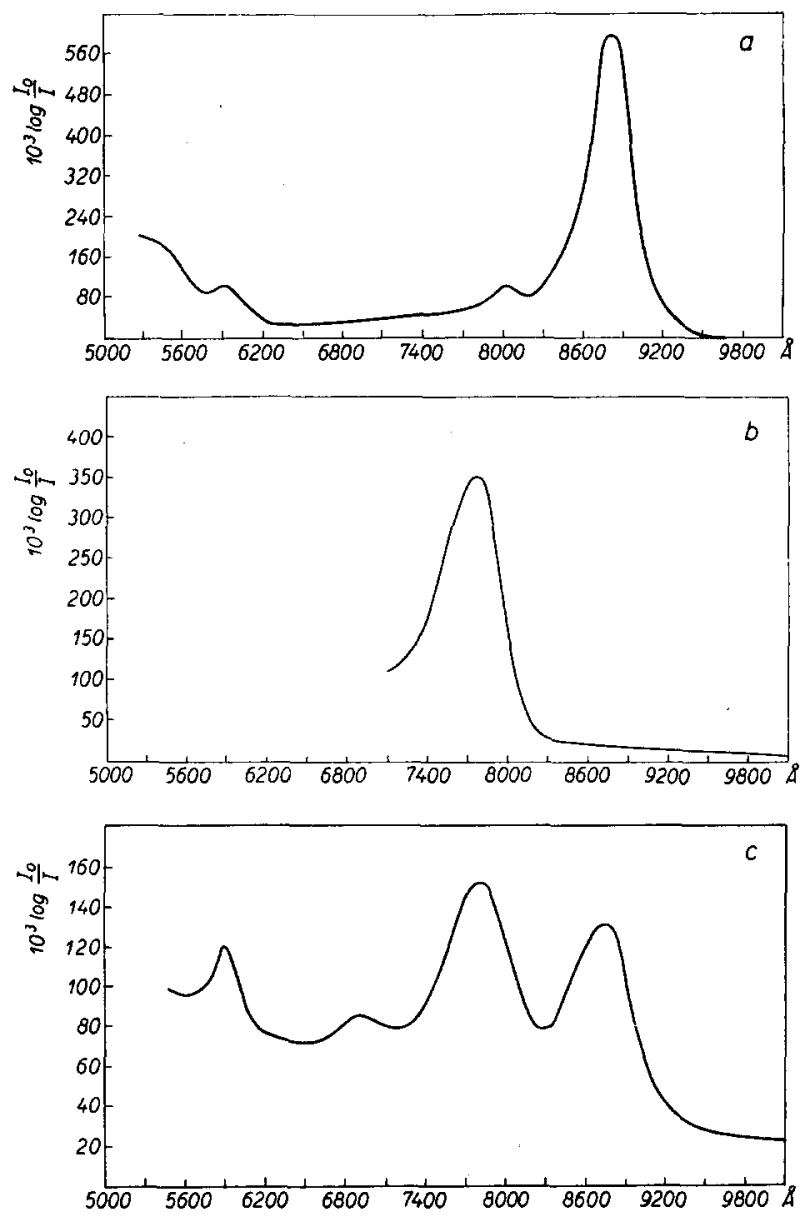

Fig. 5. Evidence of recombination of bacteriochlorophyll with its natural bearer. Absorption spectra of aqueous extract of Rhodospirillum rubrum, $a$, the same extract after addition of $80 \%$ acetone, $b$, and $c$, the latter mixture after dilution with water to an ultimate concentration of $20 \%$ acetone.

$20 \%$, the original $8800 \mathrm{~A}$ maximum reappears. However, the $7800 \mathrm{~A}$ peak shows that part of the pigment remains in the isolated state.

The stability towards light proved to differ for both of these absorption maxima. In Fig. 6 the spectra of samples of such a pigment preparation when stored either in the light or in the dark for three days are shown to be different. In contrast to the $8800 \mathrm{~A}$ peak, the $7800 \mathrm{~A}$ maximum proved to be sensitive to light.

Instead of acetone, methanol can be used. However, recombination occurs to a lower degree. The latter solvent was also used in recombination experiments with Chromatium. In these experiments the reappearance of the 8000 and $8500 \mathrm{~A}$ maxima 


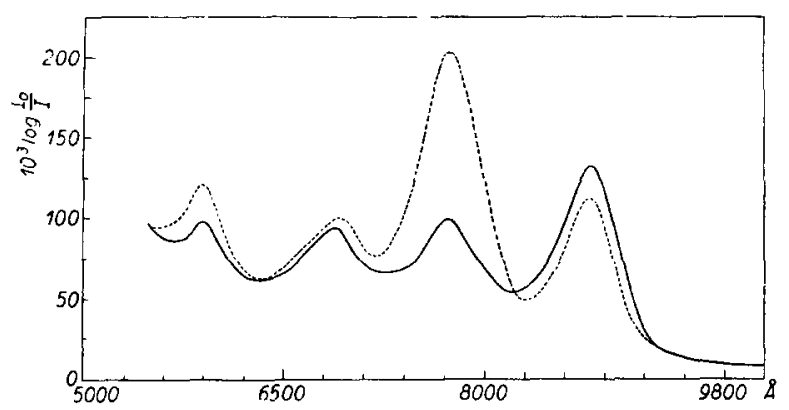

was observed after dilution of the acetone-water mixture. However, no noticeable 8800 A peak was re-established.

Fig. 6. Light-stability of the recombined pigment-bearer complex. Drawn curve: three days storage in light. Dotted curve: three days storage in the dark.

For the recombination experiments it proved necessary to work with dilute extracts; no appreciable flocculation should occur.

\section{DISCUSSION}

The spectral changes of bacteriochlorophyll dissolved in acetone upon addition of water suggest that micelle formation might occur. If this were true these micelles are responsible for an absorption band coinciding with the $8500 \mathrm{~A}$ maximum in purple bacteria with a three-peaked infrared absorption spectrum.

In vivo, the bacteriochlorophyll is coupled with a proteinaceous bearer which presumably is responsible for the observed change in absorption spectrum. In suspensions of these complexes lipides always occur. They may occur freely or in a combined state with proteins. The flocculation of extracts, when stored, as well as their reaction with SDS suggest that the bearer substance is a lipoprotein.

By adding four parts of acetone or methanol to one part of an aqueous Rhodospirillum rubrum extract the infrared spectrum is changed to that of isolated bacteriochlorophyll. Subsequent addition of watcr yielded a spectrum of a mixture of bacteriochlorophyll in the "free" and in the "in vivo" state. This result suggests that isolation followed by recombination with its original bearer is achieved for this pigment. Support for this view was obtained in experiments on the influence of light on the spectrum of the mixture in question. Considerable reduction of the $7800 \mathrm{~A}$ absorption band showed that bleaching of the "free" bacteriochlorophyll had occurred. No light-induced reduction of the 8800 A maximum was observed. Sich a light stability is a property of the "natural" pigment-bearer complexes.

With Chromatium extracts it was possible to restore only the 8500 and $8000 \mathrm{~A}$ peaks in the above way. Since, however, these maxima are considerably higher than the $8800 \mathrm{~A}$ one, observation of the latter peak may become difficult, in particular, if the restoration of the complex is only partial. Thus it may well be possible that also this band is partially restored.

\section{SUMMARY}

Absorption spectra of bacteriochlorophyll isolated from Rhodospivillum strain 4 were studied in some solvent mixtures. Addition of 9 parts of distilled water to I part of a solution of this pigment in acetone caused reduction of the $7750 \mathrm{~A}$ peak and simultaneous formation of 8500 and $9200 \mathrm{~A}$ bands. This phenomenon is reversible.

In aqueous extracts of Chromatium strain $\mathrm{D}$ a single particle weight, about $3 \cdot 10^{7}$ times the weight of a hydrogen atom, was observed. This value agrees with data from literature?

Indication that the natural pigment bearer consists of lipoproteins was obtained.

It is likely that a recombination of isolated bacteriochlorophyll with its "natural" bearer has been attained.

References p. 15 . 


\title{
REFERENCES
}

1 E. Katz AND E. C. Wassink, Enzymologia, 7 (1939) 97.

2 E. I. Rabinowitch, Photosynthesis and related Processes, Vol. II, Part I, Interscience Publ., Inc., New York, I95I.

3 E. E. Jacobs, A. E. Vatter and A. S. Holt, Arch. Biochem. Biophys., 53 (1954) 228.

${ }^{4}$ A. S. Holt añ E. E. Jacobs, Am. J. Botany, 4 I (1954) 7 Io.

5 A. A. Krasnovskit, K. K. Vojnovskaja and L. M. Kosobutskaja, Doklady Akad. Nauk S.S.S.R., 85 (1952) 389 .

6 J. G. Wakkie, Proc. Acad. Sci. Amsterdam, 38 (1935) Io82.

7 A. B. Pardee, H. K. Schachman and R. Y. Stanier, Nature, 169 (1952) 282.

${ }^{8}$ M. Macheboeuf, Discussions Faraday Soc., (1949).

$9 \mathrm{~J}$. Polonovsky, Ann. chim. (Paris), (12) 5 (1950) $67 \mathrm{I}$.

10 J. B. Thomas, J. C. Goedheer and J. G. Komen, Biochim. Biophys. Acta, 22 (1956) I.

Received December 23rd, I955

\section{THE ACTION OF ULTRAVIOLET LIGHT ON PARAMECIN AND THE CHEMICAL NATURE OF PARAMECIN*}

\author{
by \\ RICHARD SETLOW AND BARBARA DOYLE \\ Biophysics Department, Yale University, New Haven, Conn. (U.S.A.)
}

\section{INTRODUCTION}

It is important to understand the relation between nuclear duplicating particles and cytoplasmic duplicating particles. Some parts of the relationship have been worked out for Paramecium aurelia by SONNEBORN and co-workers ${ }^{1,2}$. In paramecia the cytoplasmic duplicating particles, kappa, give rise to a toxic substance called paramecin. Animals which lack kappa may be killed by this toxic substance. These animals are known as sensitives. The animals which contain kappa and liberate paramecin into the medium are known as killers.

The physical nature of kappa and of paramecin are not well known. On the basis of enzymic degradation of paramecin by proteolytic and nucleolytic enzymes, VAN WAGTENDONK has concluded that paramecin is a DNA-protein ${ }^{3}$. Though the mode of action by which paramecin kills sensitive animals is not understood, it is known that one paramecin particle is able to kill one animal4.

${ }^{\star}$ Assisted in part by a grant-in-aid from the American Cancer Society on recommendation from the Committee on Growth of the National Research Council.

References $p .20$. 